\title{
Modeling Storm-Induced Current Circulation and Sediment Transport in a Schematic Harbor
}

\author{
$\mathrm{Ji}-\mathrm{Fu}$ Zhou ${ }^{1}$ and Jia-Chun $\mathrm{Li}^{2}$
}

\begin{abstract}
A two-dimensional dynamical model is established to simulate current circulation and sediment transport induced by storm surges in a schematic harbor. The model accounts for both settling and resuspension processes of cohesive fine sediments in a salty water environment. The numerical results demonstrate that the current follows wind albeit with a time lag, and so does sediment concentration. The time lag between current and wind is of the order of interval needed for wind to transfer momentum to the whole water body. Whereas, the retarded dynamic balance of sediment entrainment and settling fluxes is responsible for the time lag between sediment concentration and current. When a tropical cyclone, or conventionally so-called typhoon in the Pacific area, is passing through the harbor, the higher sediment concentration inside the harbor is found to the right of the path rather than to the left of it. Bed deformation is found to be substantially influenced by typhoon tracks relative to the harbor. For a harbor facing east, a northward typhoon results in erosion and the southward or westward one causes deposition. Both erosion and deposition occur along the coast with little bedform variations near the harbor center.
\end{abstract}

DOI: 10.1061/(ASCE)0733-950X(2005)131:1(25)

CE Database subject headings: Typhoons; Storm surges; Currents; Sediment transport; Coastal morphology; Harbors.

\section{Introduction}

In the coastal region where tropical cyclones hit frequently, storm-induced sediment deposition and erosion play a significant role in coastal and environmental engineering. Very often, storm events cause enormous economic loss and environmental hazards (Walker and Rana 1999). A strong storm may overtop barrier islands, removing sediments from the beach or near-shore environment and depositing overwash fans across back-barrier marshes, lakes, and lagoons (Goodbred et al. 1998; Donnelly et al. 2001). In some coastal areas, tropical cyclones may account for up to $90 \%$ of the coastline retreat (Stone et al. 1997). Even more seriously, sedimentation during a single typhoon's process, which lasts only for days or even hours, may also lead to waterway blockage. As a paradigm, the navigation waterway in the Yangtze River Estuary, East China, was entirely obstructed when Typhoon 8310 went through in the summer of 1983 ( $\mathrm{Li}$ et al. 2003). Consequently, the original waterway had to be abandoned and replaced by the North Channel since then.

During recent decades, many people have studied sediment transport in coastal areas (Nielsen 1992; Rajaona 1995; Li and Davies 1996; Karambas and Koutitas 2002). However, most of

\footnotetext{
${ }^{1}$ Associate Professor, Institute of Mechanics, Chinese Academy of Sciences, Beisihuanxilu 15, Beijing, 100080, China. E-mail: zhoujf@imech.ac.cn

${ }^{2}$ Professor, Institute of Mechanics, Chinese Academy of Sciences, Beisihuanxilu 15, Beijing, 100080, China. E-mail: jcli@imech.ac.cn

Note. Discussion open until June 1, 2005. Separate discussions must be submitted for individual papers. To extend the closing date by one month, a written request must be filed with the ASCE Managing Editor. The manuscript for this paper was submitted for review and possible publication on December 8, 2003; approved on August 11, 2004. This paper is part of the Journal of Waterway, Port, Coastal, and Ocean Engineering, Vol. 131, No. 1, January 1, 2005. CASCE, ISSN 0733950X/2005/1-25-32/\$25.00.
}

these works mainly dealt with the issue under normal current and wave conditions, seldom involving the effect of storm surge. Meanwhile, marine scientists are exclusively concerned with sea level response and current pattern during storms in estuaries and bays (James et al. 1994; As-Salek and Yasuda 1995; Bode and Hardy 1997; Noye 1999).

Since a great many coastal and environmental engineering issues in near-shore regions are caused by severe erosion or deposition, considerable attention has been paid to the link between sediment transport and storm surge. Vellinga (1982) performed mobile-bed model tests to observe the process of dune erosion during storm surges. Hequette and Hill (1993) examined stormgenerated currents and offshore sediment transport on a sandy seabed based on field data analysis. Hill et al. (2003) measured waves, currents, and suspended sediment concentration in $10 \mathrm{~m}$ water depth during an intense storm with water level over $3 \mathrm{~m}$ for $15 \mathrm{~h}$. They revealed that the dominant bedforms are large threedimensional ripples formed in orbital motion flows under storm conditions. In the meantime, a great many numerical models have contributed to dune erosion or beach profiling (Zheng and Robert 1997; Keen and Glenn 2002), cross-shore sediment transport (Lee et al. 1999), etc., during storms or hurricanes, which have revealed the close relationships between coastal morphology and storm surges. There is still a good amount of literature focusing on long-term issues, such as storm effect on coast retreat (Leont'yev 2003), regional morphological response to the storm surges or high water level (Morton and Sallenger 2003; Bartholdy et al. 2004), relationships between storm frequency and shoreline dynamics (Orviku et al. 2003), etc. However, an in-depth understanding of fundamental processes governing sediment motion during storms is still urgently needed in harbor and navigation channel design. In particular, storm-induced sediment transport involves many factors, such as: Storm strength, scale and trajectory, sea bottom topography and geometric configuration, sediment textures, vegetative cover, etc. (Morton 2002). And, it is 
essential to isolate them in order to assess their effects individually. Furthermore, most of the previous studies only handled longterm geomorphologic issues, such as coastline retreat, intertidal accretion or erosion, dune recession, etc., within a time interval spanning from years to decades or even longer. But some hazards occur just during one storm event (Li et al. 2003; Fitzgerald et al. 1994). To tackle this kind of short-term issue, a real-time dynamic modeling of wind-generated currents and sediment motion is indispensable for deepening our understanding of sediment behavior under this severe disturbance.

The objective of the present study is focused on storm-induced current circulation and sediment concentration variation in a schematic harbor in order to examine the dependence of deposition/ erosion in the harbor on typhoon paths during one storm process. The contents of the current paper are planned as follows. To begin with, a numerical model to predict storm-induced current circulation and sediment transport is established. The comparison with the results of Wang's Nomograph (Bao 1991) is made to validate the proposed model. Subsequently, we have simulated current circulation, the variation of sediment concentration and bathymetric evolution in a number of cases. The finding of time lag between wind and current time series is then elucidated by momentum transfer. The temporal variations and asymmetric special distribution of sediment concentration in the harbor are analyzed in detail. Similarly, why time lag between current and sediment concentration with more moderate undulation happens is clarified as well. Finally, the influences of typhoon tracks on how much and where deposition or erosion occurs during one storm process are explored based on the previous case studies.

\section{Formulation of the Model}

\section{Modeling Storm-Induced Currents}

Storm-excited currents are governed by the depth averaged N-S equation system with the Coriolis force taken into consideration. They look like of the form:

$$
\begin{gathered}
\frac{\partial \zeta}{\partial t}+\frac{\partial(H u)}{\partial x}+\frac{\partial(H v)}{\partial y}=0 \\
\frac{\partial(H u)}{\partial t}+\frac{\partial(H u u)}{\partial x}+\frac{\partial(H u v)}{\partial y}-f H v \\
=-g H \frac{\partial \zeta}{\partial x}-\frac{1}{\rho} H \frac{\partial p}{\partial x}+\frac{1}{\rho}\left(\tau_{x}^{\zeta}-\tau_{x}^{-h}\right) \\
\frac{\partial(H v)}{\partial t}+\frac{\partial(H u v)}{\partial x}+\frac{\partial(H v v)}{\partial y}+f H u \\
=-g H \frac{\partial \zeta}{\partial y}-\frac{1}{\rho} H \frac{\partial p}{\partial y}+\frac{1}{\rho}\left(\tau_{y}^{\zeta}-\tau_{y}^{-h}\right)
\end{gathered}
$$

in the Cartesian Coordinate system, where $\zeta=$ sea surface elevation; $h=$ the water depth with respect to the mean sea level; and $H=h+\zeta .(u, v)$ denote the depth-averaged horizontal velocity components, $\rho=$ the density of sea water; $p=$ the atmospheric pressure, $\left(\tau_{x}^{\zeta}, \tau_{y}^{\zeta}\right)$ and $\left(\tau_{x}^{-h}, \tau_{y}^{-h}\right)=$ surface wind stress and the bottom drag components, respectively. $f$ indicates the Coriolis parameter $(f=2 \Omega \sin \varphi$, where $\Omega$ is the angular speed of rotation of the Earth; $\varphi$ the latitude of the harbor under $f$-plane assumption); and $g$ is the acceleration due to gravity.
As we know, the major driving forces of water motion in a tropical cyclone process are wind shear stress and air pressure applied on water surface. However, the bottom drag is also a significant factor regulating the flows in shallow water regions. All of them should be parameterized appropriately to reflect realistic physical essence.

As far as the surface and the bottom stresses is concerned, the conventional quadratic law:

$$
\begin{gathered}
\left(\tau_{x}^{\zeta}, \tau_{y}^{\zeta}\right)=\rho_{a} C_{D} W\left(W_{x}, W_{y}\right) \\
\left(\tau_{x}^{-h}, \tau_{y}^{-h}\right)=\rho C_{f} U(u, v)-\beta\left(\tau_{x}^{\zeta}, \tau_{y}^{\zeta}\right)
\end{gathered}
$$

is used, where $U=$ depth-averaged mean current speed; $\beta=0.35$ is a constant; $C_{f}=2.6 \times 10^{-3}=$ the empirical bottom friction coefficient (Yin 1985); $\rho_{a}=$ density of air; $W, W_{x}, W_{y}=$ wind speed and its $\mathrm{x}$ and y components; and the drag coefficient $C_{D}$ reads (Bao 1991):

$$
10^{3} C_{D}=\left\{\begin{array}{cc}
0.554, & W \leqslant 4.917 \\
-0.12+0.137 W, & 4.917 \leqslant W \leqslant 19.221 \\
2.513, & W \geqslant 19.221
\end{array}\right.
$$

Wang (1991) compared five widely used models of pressure field and found that combined Fujita and Takahashi formulae:

$$
p(r)=\left\{\begin{array}{cc}
p_{\infty}-\frac{p_{\infty}-p_{0}}{\sqrt{1+2(r / R)^{2}}}, & (0 \leqslant r \leqslant 2 R) \\
p_{\infty}-\frac{p_{\infty}-p_{0}}{1+r / R}, & (2 R \leqslant r<\infty)
\end{array}\right.
$$

yields more reasonable radial pressure distribution, where $R$ $=$ radius of maximum wind speed; $r=$ distance from the storm center; $p_{0}=$ the pressure at the storm center; and $p_{\infty}=$ the ambient atmospheric pressure.

The total wind field is then estimated by superposing the convection due to the typhoon's motion itself (Bao 1991)

$$
\mathbf{V}=V_{x} \exp \left(-\frac{\pi}{4} \frac{|r-R|}{R}\right) \mathbf{i}+V_{y} \exp \left(-\frac{\pi}{4} \frac{|r-R|}{R}\right) \mathbf{j}
$$

and the gradient wind field

$$
|\mathbf{G}|=-\frac{f}{2} r+\sqrt{\frac{f^{2}}{4} r^{2}+\frac{r}{\rho_{a}} \frac{d p(r)}{d r}}
$$

in tropical cyclone, where $\mathbf{G}=$ gradient wind vector, rotating counterclockwise in the north hemisphere. The magnitude of wind speed $G$ grows rapidly with $r$ from zero at the typhoon center up to the maximum one right at the cyclone eye edge, and then drops very slowly with $r$. Considering mobile storm, the total wind field is found asymmetrical with the greatest wind occurring to the right of the tropical cyclone in the north hemisphere.

To validate the model, we have simulated water motion in an open sea domain of $600 \mathrm{~km}$ long along the coast and $192 \mathrm{~km}$ wide with the depth linearly increases from $5 \mathrm{~m}$ to $103 \mathrm{~m}$ seaward. The calculated surge peaks excited by tropical cyclones that move perpendicularly landward at a speed of $21.6 \mathrm{~km} / \mathrm{h}$ but with a different pressure drop $\Delta p=p_{\infty}-p_{0}$ and maximum wind radius $R$ is shown in Fig. 1. The air pressure drop ranges from $20 \mathrm{hPa}$ for a weak storm to $100 \mathrm{hPa}$ corresponding a very strong one. And the maximum wind radius varies from $10 \mathrm{~km}$ to as large as $90 \mathrm{~km}$. As compared with the results in Wang's Nomograph (Bao 1991), the error of the present model at most is within $0.10 \mathrm{~m}$. 

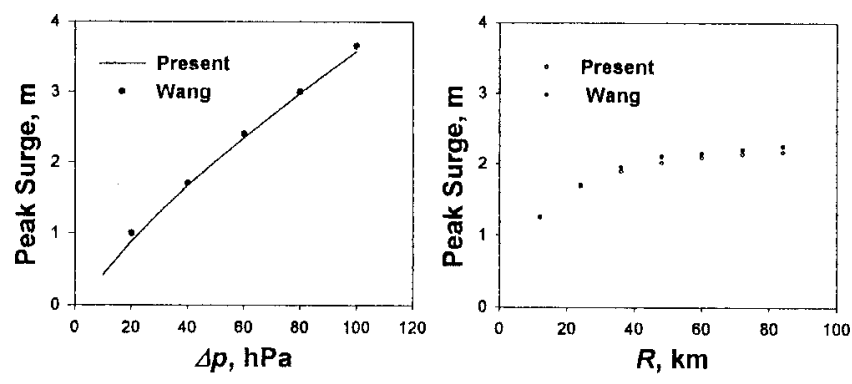

Fig. 1. Peak surges corresponding to different pressure drop $\Delta p$ and wind radius $R$

\section{Modeling Storm-Induced Sediment Transport}

Under the assumption of dilute concentration, the passive scalar transport model (Zhou and Li 2000; Zhou et al. 2000):

$$
\frac{\partial(H c)}{\partial t}+\frac{\partial(u H c)}{\partial x}+\frac{\partial(v H c)}{\partial y}=\frac{\partial}{\partial x}\left(D_{x} H \frac{\partial c}{\partial x}\right)+\frac{\partial}{\partial y}\left(D_{y} H \frac{\partial c}{\partial y}\right)+S
$$

is used to predict sediment transportation, where $c=$ depth-averaged sediment concentration; $D_{x}, D_{y}=$ horizontal sediment diffusivity; and $S=$ source/sink term due to the exchange of suspended load and bed load and expressed as the difference of entrainment and settling fluxes:

$$
S=E_{n} \rho_{s}-\omega C_{b}
$$

where $\rho_{s}=$ density of sediment particles; and $\omega=$ settling velocity. In coastal areas, salinity usually exhibits a significant effect on sediment settlement due to flocculation. Therefore, we should simultaneously solve the salinity convection-diffusion equation to estimate the settling speed of sediment particles. Nevertheless, salinity may be regarded as almost uniform in strongly disturbed and fully mixed seawater during the storm. Namely, a constant salinity of $35 \mathrm{ppt}$ is commonly accepted in this circumstance. According to Chien and Wan (1999), sediment particles finer than $0.01 \mathrm{~mm}$ in diameter flocculate easily in a salty water environment. Thus, the settling velocity of sediment depends on salinity and sediment concentration instead of particle size (Fig. 2).

$C_{b}$, the sediment concentration at the bottom in Eq. (10), can be related to the depth mean sediment concentration by the exponential concentration formula:

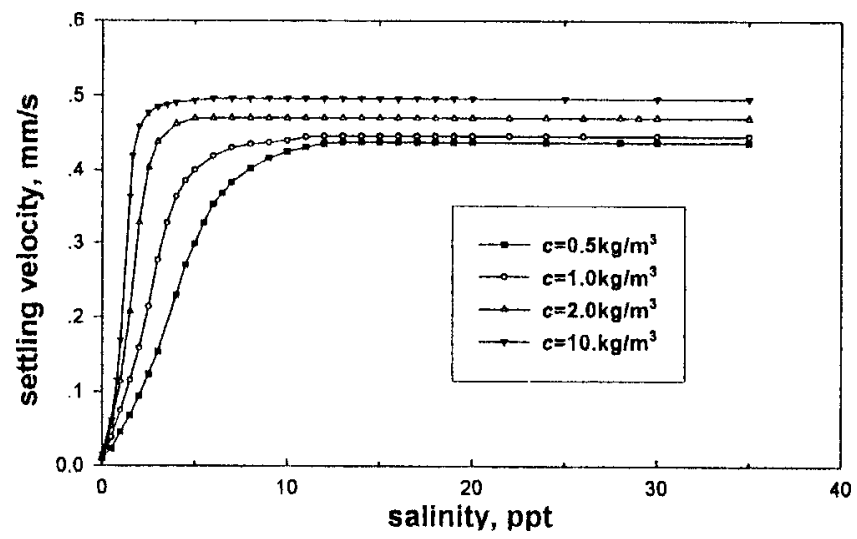

Fig. 2. Dependences of settling velocity of fine sediments on salinity and sediment concentration (Chien and Wan 1998)

$$
\frac{c_{z}}{C_{b}}=e^{-\omega(z-a) / \varepsilon_{z}}
$$

according to which $C_{b}$ can be expressed in term of the depth mean concentration (Zhou et al. 2000)

$$
C_{b}=K\left[\frac{\omega(H-a)}{\varepsilon_{z}}\left(1-e^{-\omega / \varepsilon_{z}(H-a)}\right)^{-1}\right] c
$$

where $c_{z}=$ sediment concentration at the height of $z$ above the bottom; $\varepsilon_{z}=\kappa u_{*} H / 6=$ vertical sediment diffusivity $(\kappa=0.4$ is the von Karman's constant and $u_{*}$ is the friction velocity); $a=$ reference height equal to the diameter of bed grains; and $K=1.08=$ correction factor accounting for the deviation of concentration profile from Eq. (11).

$E_{n}$ in Eq. (10) is the so-called pick-up function representing sediment flux in volume entrained up from the unit bed area per unit time. The turbulent bursting-based entrainment function proposed by Cao (1997):

$$
E_{n}=P \sqrt{\frac{\rho_{s}-\rho}{\rho g}} d\left(\frac{\tau^{\prime}}{\tau_{c}}-1\right) \frac{\tau^{\prime}}{\rho_{s}-\rho}
$$

is used, in which $d=0.009 \mathrm{~mm}$, the grain diameter of sediment about the particle size of suspended sediments in the Yangtze River Estuary, China; $\tau^{\prime}=$ skin friction of bed shear stress responsible for sediment incipience; $\tau_{c}=$ critical incipient stress of bed sediments; and

$$
P=\frac{\lambda C_{0 b}}{\nu T_{B}^{+}} \sqrt{\frac{\rho_{s}-\rho}{\rho} g}
$$

where $C_{0 b}=$ volumetric concentration $\left(\mathrm{m}^{3} / \mathrm{m}^{3}\right)$ of bed material; $\nu=$ the viscosity of water; $\lambda \approx 0.02=$ the averaged area of all bursts per unit bed area; and $T_{B}^{+} \approx 100=$ nondimensional bursting period (Cao 1997).

The skin friction of bed shear stress, $\tau^{\prime}$, is estimated after Einstein's drag-partition formula as $\tau^{\prime}=\rho g R^{\prime} J$, where $R^{\prime}$ is the portion of the flow hydraulic radius that corresponds to the skin friction and is computed iteratively from a Keulegan-type profile

$$
\sqrt{\frac{u^{2}+v^{2}}{g R^{\prime} J}}=\frac{1}{\kappa} \ln \left(\frac{R^{\prime}}{2.718 z_{0}}\right)
$$

where $J=$ water surface slope; and $z_{0}=$ roughness length of the sediment bed equal to one-thirtieth of the grain diameter (Wilcock 1993).

The critical incipient stress is defined by Tang's formula (Chien and Wan 1998)

$$
\tau_{c}=\frac{1}{77.5}\left[3.2\left(\rho_{s}-\rho\right) d+\left(\frac{\rho_{b}}{\rho_{b 0}}\right)^{10} \frac{k}{d}\right] g
$$

where $k=2.9 \times 10^{-5} \mathrm{~kg} / \mathrm{m} ; \rho_{b 0}=1600 \mathrm{~kg} / \mathrm{m}^{3}=$ bulk density of compact bed material; and $\rho_{b}=$ bulk density of bed material, which varies during the processes of sediment deposition and resuspension, with its maximal value being $\rho_{b 0}$. This formula introduces the effect of fine particles, between which a kind of cohesive force exists, counteracting sediment initiation. The first term on the right of Eq. (16) represents the effect of net sediment weight under water, and the second term the effect of the cohesive force, which may account for a large portion of the critical stress for very fine particles.

Based on the mass conservation law, the bed deformation obeys the following equation: 


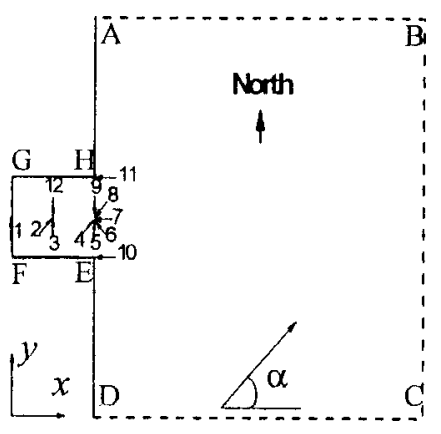

Fig. 3. The sketch of calculated domain and the inclination of different typhoon tracks: $\alpha=45^{\circ}: 2$ and $4 ; \alpha=90^{\circ}: 1,3$, and 5; $\alpha=135^{\circ}: 6 ; \alpha=180^{\circ}: 7,10$, and $11 ; \alpha=225^{\circ}: 8$; and $\alpha=270^{\circ}: 9$ and 12. A: $(100,500)$; B: $(500,500)$; C: $(500,0)$; D: $(100,0)$; E: $(100,200)$; F: $(0,200) ; \mathrm{G}:(0,300)$; and H: $(100,300)$

$$
\rho_{s 0} \frac{\partial \eta}{\partial t}+S=0
$$

where $\eta$ represents the bed elevation with respect to initial sea bed position; and $\rho_{s 0}=$ dry bulk density of bed material. In the present study, we have not considered the bed load in the source term since it only occupies a very small portion of total sediment load in the case of fine sediment.

Apparently, we may have a simple relation between the volumetric concentration $C_{0 b}$, the bulk density $\rho_{b}$, and the dry bulk density $\rho_{s 0}$ of bed material as follows:

$$
C_{0 b}=\frac{\rho_{s 0}}{\rho_{s}}=\frac{\rho_{b}-\rho}{\rho_{s}-\rho}
$$

As a matter of fact, they generally vary from time to time, especially in coastal areas where sediment settling and resuspension occur time and again with waves and tides. In an ideal case of mostly dense compact sediment particles, we yield the maximal value of $C_{0 b} \approx 0.6$ and $\rho_{b} \approx 2000 \mathrm{~kg} / \mathrm{m}^{3}$, correspondingly if $\rho_{s}$ $=2650 \mathrm{~kg} / \mathrm{m}^{3}$. Nevertheless, in situ observation indicates that the situation is quite different due to the existing water membrane between sediment particles, which prevents sediment particles from becoming densely arranged. As a result, the maximal value of $\rho_{b}$ is actually approximate to $\rho_{b 0}$. On the other hand, the minimal $\rho_{b}$ corresponds to that of mud, which contains a certain amount of water and is formed on the bed surface. The bulk density of mud is about $1,100 \mathrm{~kg} / \mathrm{m}^{3}$. For the sake of convenience, we only use the averaged value of $\rho_{b}$ instead in the calculation.

\section{Boundary and Initial Conditions}

Since the motion is generated at rest, the sediment concentration is negligibly low. That is to say, we may approximately assume $u=v=c=0$ everywhere at the initial moment. The initial water level is set to the hydrostatic height corresponding to the initial pressure field.

Along the coastline, the nonslip conditions for current and vanished sediment flux are specified. At the open boundaries, the water level is prescribed by hydrostatic principle, and sediment concentration is also assumed to be very low.

\section{Schematic Harbor Study}

An ideal schematic harbor of $100 \mathrm{~km}$ square [EFGH in Fig. 3] is

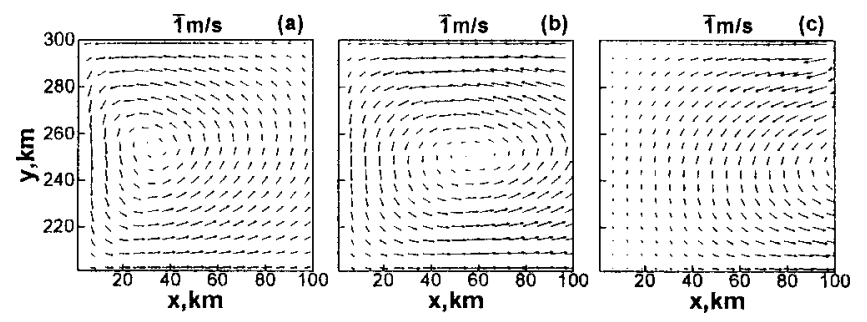

Fig. 4. Current vectors in the harbor for the case of track 7, showing current circulation core being behind the typhoon eye, which is at (a): $(0,250)$ when $t=27.78 \mathrm{~h}$; (b): $(50,250)$ when $t=25 \mathrm{~h}$; and (c): $(100,250)$ when $t=22.22 \mathrm{~h}$

considered. To avoid the influence of the boundary as much as possible, the calculated domain is extended to a $500 \mathrm{~km}$ square area. The sea bottom of the domain is assumed to be flat and $10 \mathrm{~m}$ below the mean sea level (the Datum). In Fig. 3, $|\mathrm{AB}|=400 \mathrm{~km}$, $|\mathrm{BC}|=500 \mathrm{~km}$, and the solid line represents the coast. The upwind difference scheme is selected to discretize the governing equations. The domain is meshed with grid size $\Delta x=2,000 \mathrm{~m}$, $\Delta y=2,000 \mathrm{~m}$ and refined ones $\Delta x^{\prime}=1,000 \mathrm{~m}, \Delta y^{\prime}=1,000 \mathrm{~m}$ in the harbor. The time step is assumed $120 \mathrm{~s}$ for current calculation and $240 \mathrm{~s}$ for sediment transport and bed deformation.

To examine the influences of the typhoon path on sediment transport and bed deformation in the harbor, 12 typical straight routes (denoted by number 1 to 12 in Fig. 3) are considered in the simulation. It is assumed that the center of typhoon moves directly over or by the harbor. Each route is defined by a reference location and an incident angle $\alpha$ described as that between typhoon's moving direction and axis $x$. The incident angle ranges from $45^{\circ}$ to $270^{\circ}$ with an increment $45^{\circ}$. The reference location for track 1 is the midpoint of the FG side. The reference point for tracks 2, 3, and 12 is the harbor center. The harbor mouth center is the reference location for tracks 4 to 9 . And tracks 10 and 11 refer to the location $\mathrm{E}$ and $\mathrm{H}$, respectively. Each typhoon is supposed to originate from $400 \mathrm{~km}$ away from its reference point at the initial moment $t=0$. The fundamental parameters of the typhoon are as follows: The maximum wind radius is $48 \mathrm{~km}$; the pressure drop at its center is $50 \mathrm{hPa}$; and the moving speed is $5 \mathrm{~m} / \mathrm{s}$, i.e., $18 \mathrm{~km} / \mathrm{h}$. So, each typhoon passes the reference point at $t=22.22 \mathrm{~h}$.

\section{Storm-Induced Current Circulation in the Harbor}

Once a typhoon formed in the open sea traverses the harbor, fierce wind stress and air pressure depression tremendously-stir the water in the region. Fig. 4 shows the flow patterns in the harbor at three different moments in the process of typhoon 7. Due to the rotating wind field, the water in the harbor flows approximately in a circular trajectory with a central region nearly at rest corresponding to the calm typhoon eye. This central region slowly follows the moving of the typhoon eye albeit with a time delay. The time lag between current and wind speed is also observed in Fig. 5 of time series plot distinctly. All of the peaks and valleys in the current speed obviously occur behind those in wind speed variation. The average time lag is about $1 \mathrm{~h}$ or so. As a matter of fact, the time interval for momentum to transfer from atmosphere to the whole water body is responsible for this kind of delay. We may roughly estimate this time interval as follows. Consider a water body of depth of $H$ with an area of $A$ excited by the wind, 


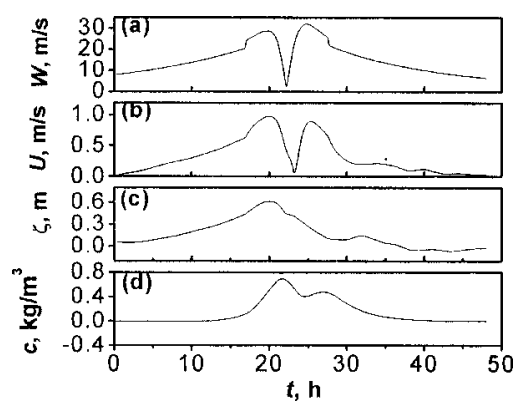

Fig. 5. Time series of: (a) wind speed, (b) current velocity, (c) water level, (d) sediment concentration. Salinity $=35 \mathrm{ppt}$.

from still to a speed of $U$ within a time interval of $\Delta t$, which can be estimated as $\Delta t=\rho H U / \tau^{\varsigma}$ by equating the applied impulse $\tau^{\varsigma} A \Delta t$ to the momentum increment $\rho H A U$. In the present circumstance, we have $\Delta t \sim 5,000 \mathrm{~s}$ with $H \sim 10 \mathrm{~m}, U \sim 0.5 \mathrm{~m} / \mathrm{s}, \tau^{\mathrm{s}}$ $=\rho_{a} C_{D} W^{2}=1.25 \times 0.0025 \times 20^{2} \sim 1 \mathrm{~N} / \mathrm{m}^{2}$. We have observed that the simulated time lag between current and wind speed is of the same order as the estimation. Obviously, we may further conclude that the deeper the water and the weaker the storm, the longer the time interval needed.

The flow pattern is characterized by an additional salient feature, namely, the current speed to the right of the track is larger than that to the left owing to the superposition of the counterclockwise gradient wind on the typhoon's motion itself. We have learned that typhoon's moving enhances the wind speed to the right of its track and diminishes the wind speed to the left of it. At a specific position, however, wind speed grows with the approaching of storm and then reduces with its departure. If we stay near the calm eye, two peaks with a valley in-between may be felt [Fig. 5(a)]. It should be particularly stressed that the current circulation pattern is significantly influenced by the typhoon's parameters (including atmospheric pressure drop, maximum wind radius, and moving speed) and water depth, etc., Zhou et al. (2001) have discussed these factors' effects in more detail. It is just the characteristics of the circulation pattern that govern sediment motion in the harbor as we may see in the following sections.

\section{Variations of Sediment Concentration in the Harbor}

During storms, severe wind stress forces water to circulate and then sediment to suspend. Fig. 5(d) shows the variation of sediment concentration at the mouth center during a storm process. For comparison, the current speed is also plotted in the same diagram. When the typhoon is far from the harbor, wind shear stress at the sea surface is weak and so current speed is too small to entrain sediment particles. As the typhoon is approaching, the current is rapidly accelerated, thus resulting in the remarkable enhancement of bed shear stress. During the initial stage, the sediment concentration is very low as the current speed is less than $0.4 \mathrm{~m} / \mathrm{s}$, implying that almost no sediment particles are suspended from the bed until the bottom stress reaches the shear stress threshold. As the bed shear stress exceeds the threshold for sediment incipience, sediment particles start to suspend from the bed. Hence, it is not surprising that the sediment concentration grows with wind speed since then. Therefore, we believe that the critical current speed for sediment initiation is approximately $0.4 \mathrm{~m} / \mathrm{s}$.
The salient feature of both current speed and sediment concentration time series possessing two peaks is attributed to the existing calm typhoon eye. We may also see from Fig. 5 that the variation of sediment concentration follows the current speed variation with about a $1 \mathrm{~h}$ lag behind. The fact implies that less energy from current is needed to keep sediments in suspension than that to erode them from the bed. In other words, the entrainment starts later than current's rise due to shear stress threshold and stops later than current's reduction because the entrainment is still dominant over the settling in a certain period. The balance between suspension and settling can hardly be reached instantly. The retarded dynamic balance between them may reasonably account for this time lag.

Another feature manifested in Fig. 5 is the moderate undulation in concentration curves. In contrast, we may see sharp rising and falling in the current speed diagram with steep valley. That is to say, although the concentration begins to decrease behind its peak, it starts to increase again prior to dropping to a very low value as the current speed does. This is because of the long sluggish falling process or very small settling velocity of finer sediment particles. In the case of salinity of 35 ppt with settling velocity of the order of $0.4 \mathrm{~mm} / \mathrm{s}$ (Fig. 2), this asymptotic process to a new dynamic equilibrium can last for $7 \mathrm{~h}$ or so, which is just the order of the time interval for particles at the sea surface to entirely fall to the seabed. However, the abrupt current speed variaion makes the entrainment flux immediately larger than the settling flux in much shorter time duration. It can be seen in Fig. 5(b) that current velocity lower than the critical velocity of $0.4 \mathrm{~m} / \mathrm{s}$ for sediment incipience only lasts for about $2 \mathrm{~h}$ near the current speed valley. Actually, we may approximately estimate the concentration valley by simply removing sediments deposited on the bed during a nonentrainment period from the whole water column. For example, as salinity equals $35 \mathrm{ppt}$, sediment concentration is $0.673 \mathrm{~kg} / \mathrm{m}^{3}$ at the beginning of the nonentrainment period. During this period, sediment particles in the water column below the height of $2.88 \mathrm{~m}$ from the bed may deposit to the bed. Removing this part (approximately 30\%) of suspended sediment from water, we may roughly estimate the concentration valley as $0.673 \times 71.2 \%=0.479 \mathrm{~kg} / \mathrm{m}^{3}$, very close to the numerical valley $0.448 \mathrm{~kg} / \mathrm{m}^{3}$.

With the typhoon's departure, current speed becomes smaller until it is below the critical velocity for sediment initiation. Then, sediment particles are no longer entrained into the water body and the suspended particles keep falling down to the bottom. However, this process lasts for a long time because the settling flux becomes smaller as sediment concentration reduces. This sluggish process is obviously displayed in Fig. 5(d), where settling lasts for a period of nearly $10 \mathrm{~h}$, the order of settlement in still water. Fig. 6 shows the concentration contours in the harbor at several moments during the storm of track 7 with $\alpha=180^{\circ}$, exhibiting that the sediment concentration in the whole harbor varies with time in an analogous manner to that at the mouth center displayed in Fig. 5(d). That is, the concentration increases with the approaching of a typhoon and decreases with its departure. Moreover, the characteristics of concentration distribution rely heavily on the wind and current field. Sediment concentration in the right area is greater than that in the left area corresponding to the aforementioned flow pattern. The water body with high concentration is found to be located about one wind radius from the typhoon center. Sediment concentration turns out to be very low along the path of the typhoon eye due to the negligible wind and current speed nearby. 


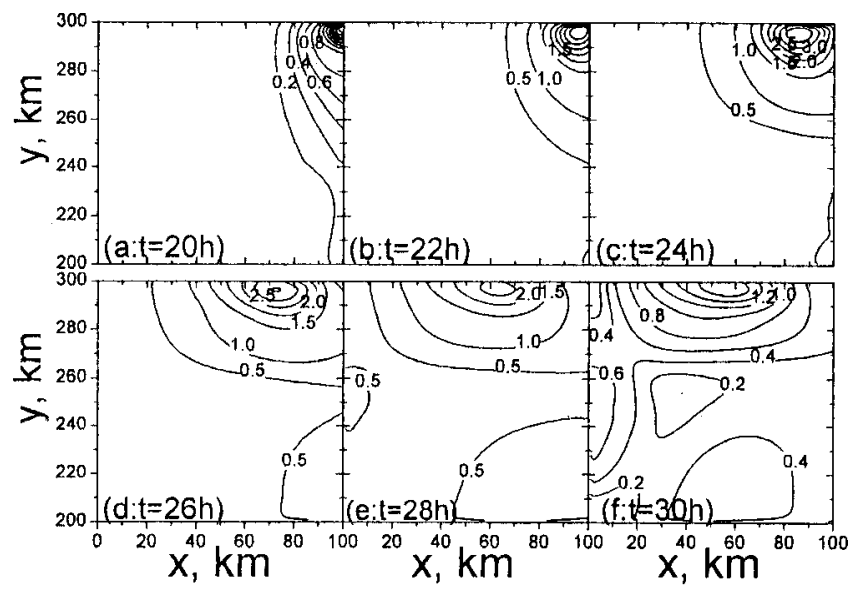

Fig. 6. Contours of sediment concentration in the harbor at different time for the case of typhoon 7

\section{Sedimentation and Bathymetric Evolution in the Harbor}

Based on the previous discussion, we are now in a position to examine sea bottom evolution processes during storms in the present section. Consider that the seabed ultimately varies from the initial elevation $\eta_{0}$ to the final elevation $\eta_{n}$. Then the difference $\Delta \eta=\eta_{n}-\eta_{0}$ represents scour (if $\Delta \eta<0$ ) or deposition (if $\Delta \eta>0)$ thickness. Integrating $\Delta \eta$ over the whole harbor domain, we yield the total scour or deposition volume:

$$
V_{s d}=\iint_{E F G H} \Delta \eta \cdot d x \cdot d y
$$

which is obviously a track-dependent quantity. A positive (or negative) $V_{s d}$ means aggradation (or degradation) in the harbor. Table 1 lists $V_{s d}$ for 12 typhoon tracks. It is found that aggradation occurs when the typhoon moves southward or westward. In contrast, a northward typhoon degrades the bed. It is also apparent that both the direction and the relative position of typhoon routes considerably influence the scour or deposition volume. With the sign of $V_{s d}$ changed, the former may even cause bathymetric evolution from degradation to aggradation, or vice versa, whereas the latter only affects the amount of deposition (or scour) quantitatively. The largest deposition occurs as the typhoon passes through the harbor mouth center.

Fig. 7 is a diagram for bed aggradation or degradation in the harbor. We find that aggradation begins at the northeast corner and grows gradually southwest. At the same time, degradation develops from the southeast corner to the northwest region. Little bed change happens near the track.

Alternatively, we may also estimate the total amount of sediment degradation (or aggradation) in a different way. Let's look at the variation of sediment flux profile at the mouth section:

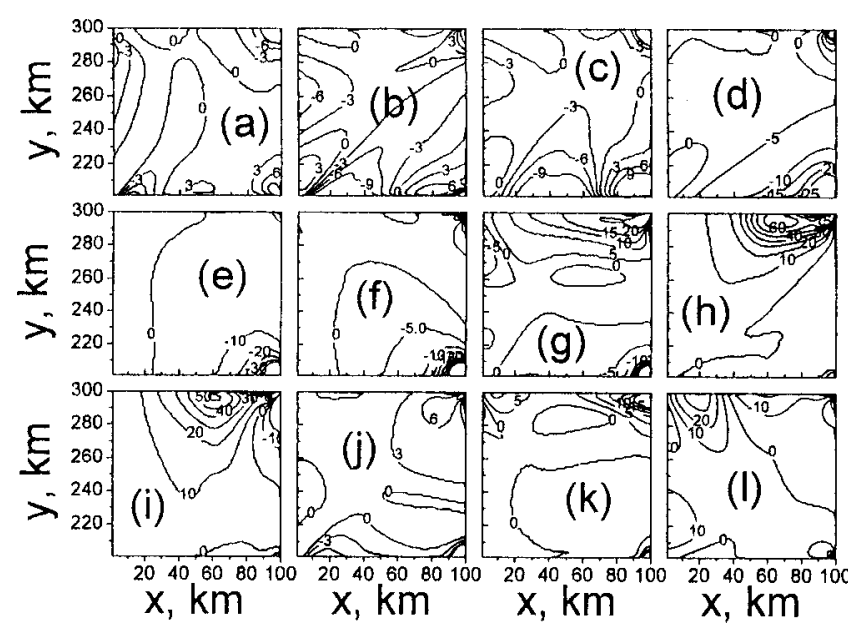

Fig. 7. Contours of scour (negative) and deposition (positive) thickness ( in millimeters) in the harbor for different tracks: (a) track 1 ; (b) track 2; (c) track 3; (d) track 4; (e) track 5; (f) track 6; (g) track 7; (h) track 8; (i) track 9; (j) track 10; (k) track 11; and $(\ell)$ track 12

$$
q(y, t)=u \cdot(h+\zeta) \cdot \Delta y \cdot c
$$

to elucidate the implied mechanism. Obviously, the sign of $q$ depends on the current speed component $u$ there. The current carries sediment into the harbor if $q$ is negative, whereas the current emits sediment into open sea if $q$ is positive. Fig. 8 displays the sediment flux profile on the mouth section at seven moments during storms for tracks 6 and 8. The flux is negligible in the time interval beyond the range $18 \mathrm{~h}<t<32 \mathrm{~h}$. Owing to the time lag between sediment concentration and current speed time series (Fig. 5), the seaward blowing wind exports more sediment from the harbor via the south subsection and the inward blowing wind imports less sediment from the open sea via the north subsection in the case of track 6 [Fig. 8(a)]. Therefore, bed degradation occurs in the southeast part of the harbor as shown in Fig. 7(a). Analogously, Fig. 8(b) accounts for bed changes demonstrated by Fig. 7(c) for track 8. Therefore, it is the flow field pattern and the time lag between sediment concentration and current speed that primarily regulate the whole sediment transport process, such as sediment incipient motion, suspension, settling, bed evolution, etc., in the harbor. Apparently, the time lag between sediment concentration and current speed is also closely associated with typhoon's intensity and soil properties.

\section{Concluding Remarks}

The present study is mainly dedicated to the examination of the effects of storm surge on the short-term bathymetric evolution, about which coastal and environment engineers are concerned. A physical model is established to simulate storm-induced current and sediment transport processes in a schematic harbor. The

Table 1. Scour (-) or Deposition (+) Volume in the Harbor for Different Typhoon Tracks

\begin{tabular}{ccccccccccccc}
\hline Track & 1 & 2 & 3 & 4 & 5 & 6 & 7 & 8 & 9 & 10 & 11 & 12 \\
\hline $\begin{array}{c}V_{s d} \\
\left(\mathrm{Mm}^{3}\right)\end{array}$ & -2.9 & -20.6 & -19.5 & -38.8 & -46.2 & -27 & 23.3 & 73.8 & 73.4 & 8.7 & 8.5 & 24.1 \\
\hline
\end{tabular}



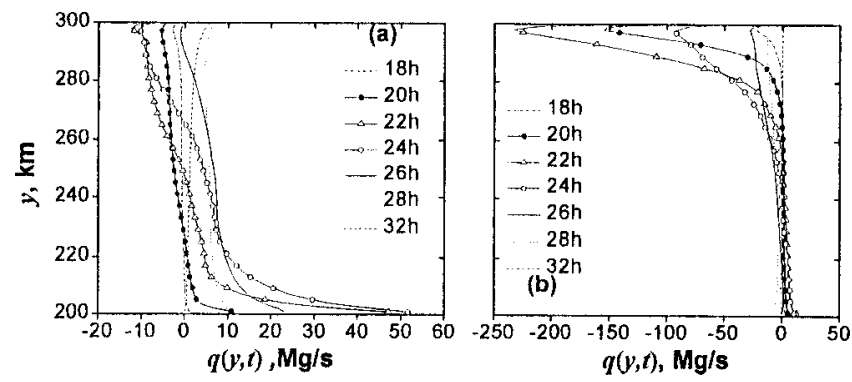

Fig. 8. Time-dependent sediment flux profile along the mouth section for (a) track 6 and (b) track 8

model validation and mechanism analysis show that all of the assumptions and parameterization in subgrid processes appear to be adequate and reasonable.

The simulated result reveals that the water particles in the harbor circulate approximately in a circular trajectory with a central region nearly at rest corresponding to the calm typhoon eye when the storm is coming over the site. The current speed to the right of the path is larger than to the left of it due to the superposition of counter-clockwise wind and the typhoon's movement. The most significant finding of this study is that the current speed variation lags behind wind speed due to the duration needed for momentum transfer from air to water body. Therefore, such a time lag can approximately be estimated by the momentum conservation law, which is responsible for why the deeper the harbor and the weaker the storm, the longer the time lag.

Similarly, the sediment concentration increases and decreases following current speed variation with a time lag as well. Nevertheless, this time lag is attributed to the dynamic adjustment process to balance sediment entrainment and settling in the benthal layer. Sediment can hardly be suspended until current speed exceeds the threshold. On the other hand, sediment concentration continues to increase if entrainment is still dominant over settling even if the wind speed starts to decrease. This retarded dynamic balance may convincingly account for the time lag between current speed and sediment concentration.

We further find that typhoon tracks have a significant impact on sea bottom evolution. While the typhoon track's direction determines erosion or deposition in the harbor, the relative position of the track regulates the magnitude of erosion/deposition. It is the magnitudes and directions of the current vectors at the mouth and the time lag between sediment concentration and current speed that dominantly regulate sediment delivery processes between the harbor and open sea. Generally speaking, the northward typhoon results in harbor erosion, and the southward or westward one causes deposition. Both erosion and deposition take place along the coastline. Little variation of bed happens near the harbor center.

In order to examine sediment motion in more complicated circumstances, further research should be directed to the effects of marine soil property, sea bed topography, and tide-storm surge interaction.

\section{Acknowledgments}

The writers greatly appreciate the financial support of the National Natural Science Foundation of China (Grant Nos. 10332050 and 10002023), and the Opening Research Foundation of the State Key Laboratory of Water Resources and Hydropower Engineering Science, Wuhan University (No. 2003B003).

\section{Notation}

The following symbols are used in this paper:

$a=$ reference height;

$C_{b}=$ sediment concentration at the bottom;

$C_{D}=$ wind stress coefficient;

$C_{f}=$ bottom friction coefficient;

$C_{0 b}=$ volumetric concentration of bed material;

$c=$ depth-averaged mean sediment concentration;

$c_{z}=$ sediment concentration at the height of $z$ above the bottom;

$D_{x}, D_{y}=$ horizontal sediment diffusivity;

$d=$ grain diameter of sediment;

$E_{n}=$ pick-up function representing sediment flux in volume entrained up from the unit bed area per unit time;

$f=$ Coriolis parameter;

$\mathbf{G}=$ gradient wind vector;

$g=$ gravitational acceleration;

$H=$ total water depth;

$h=$ water depth with respect to the mean sea level;

$J=$ water surface slope;

$K=$ a correction factor;

$k=$ a constant;

$P=$ a factor related to the averaged area of all bursts per unit bed area and the nondimensional bursting period;

$p=$ atmospheric pressure;

$p_{0}=$ pressure at the storm center;

$p_{\infty}=$ ambient atmospheric pressure;

$q=$ horizontal sediment flux at the harbor mouth section;

$r=$ distance from the storm center;

$R=$ radius of maximum wind speed;

$R^{\prime}=$ part of hydraulic radius that corresponds to the skin friction;

$S=$ a source/sink expressing balance of sediment entrainment and settling fluxes;

$T_{B}^{+}=$nondimensional bursting period;

$U=$ depth mean current velocity;

$u, v=$ components of $U$ in $x, y$ directions;

$u_{*}=$ shear velocity;

$V_{s d}=$ scour or deposition volume in the harbor;

$\mathbf{V}=$ velocity vector produced by typhoon's movement;

$V_{x}, V_{y}=$ components of $\mathbf{V}$ in $x, y$ directions;

$W=$ wind speed;

$W_{x}, W_{y}=$ components of $W$ in $x, y$ directions;

$z_{0}=$ roughness length for bed sediment;

$\alpha=$ incident angle of typhoon defined as that between typhoon's moving direction and axis $x$;

$\beta=$ a constant;

$\Delta \eta=$ deposition $(\Delta \eta>0)$ or scour $(\Delta \eta<0)$ thickness of bed;

$\varepsilon_{z}=$ vertical sediment diffusivity;

$\zeta=$ sea surface level.

$\eta=$ sea-bed elevation;

$\eta_{0}=$ initial sea-bed elevation;

$\eta_{n}=$ sea-bed elevation at the end of computation;

$\kappa=$ von Karman's constant; 


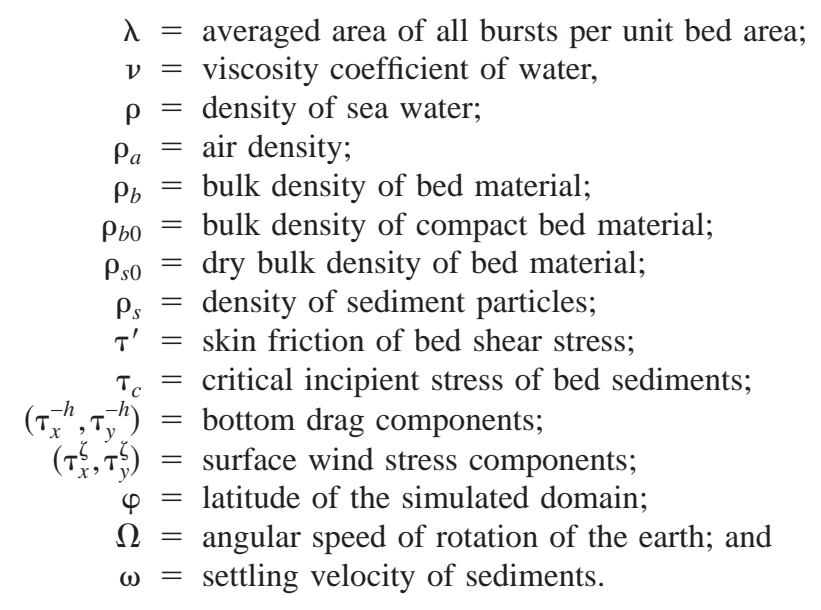

\section{References}

As-Salek, J. A., and Yasuda, T. (1995). "Comparative study of the storm surge models proposed for Bangladesh: Last developments and research needs." J. Wind. Eng. Ind. Aerodyn., 54/55, 595-610.

Bao, C. L. (1991). Chap. 3, "Storm surges." Oceanic disasters and their forecasting, China Ocean Press, Beijing, China, 43-88 (in Chinese).

Bartholdy, J., Christiansen, C., and Kunzendorf, H. (2004). "Long-term variations in backbarrier salt marsh deposition on the Skallingen peninsula-the Danish Wadden Sea." Mar. Geol., 203(1-2), 1-21.

Bode, L., and Hardy, T. A. (1997). "Progress and recent developments in storm surge modeling." J. Hydraul. Eng., 123(4), 315-331.

Cao, Z. X. (1997). "Turbulent bursting-based sediment entrainment function." J. Hydraul. Eng., 123(3), 233-236.

Chien, N., and Wan, Z. H. (1999). Mechanics of sediment transport, ASCE, Reston, Va.

Donnelly, J. P., et al. (2001). "700 yr sedimentary record of intense hurricane landfalls in southern New England." Geol. Soc. Am. Bull., 113(6), 714-727.

Fitzgerald, D. M., Vanheteren, S., and Montello, T. M. (1994). "Shoreline processes and damage resulting from the Halloween-Eve storm of 1991 along the north and south shores of Massachusetts Bay, USA." J. Coastal Res., 10(1), 113-132.

Goodbred, S. L., Wright, E. E., and Hine, A. C. (1998). "Sea-level change and storm-surge deposition in a late Holocene Florida salt marsh." $J$. Sediment Res., 68(2), 240-252 Part B.

Hequette, A., and Hill, P. R. (1993). "Storm-generated currents and offshore sediment transport on a sandy shoreface, Tibjak beach, Canadian Beaufort Sea." Mar. Geol., 113(3-4), 283-304.

Hill, P. R., Meule, S., and Longuepee, H. (2003). "Combined-flow processes and sedimentary, structures on the shoreface of the wavedominated Grande-riviere-de-la-Baleine delta." J. Sediment Res., 73(2), 217-226.

James, F. P., Sanford, T. B., and Froristall, G. Z. (1994). "Forced stage response to a moving hurricane." J. Phys. Oceanogr., 24, 233-260.

Karambas, T. V., and Koutitas, C. (2002). "Surf and swash zone morphology evolution induced by nonlinear waves." J. Waterw., Port, Coastal, Ocean Eng., 128(3), 102-113.
Keen, T. R., and Glenn, S. M. (2002). "Predicting bed scour on the continental shelf during Hurricane Andrew." J. Waterw., Port, Coastal, Ocean Eng., 128(6), 249-257.

Lee, C. E., Kim, M. H., and Edge, B. L. (1999). "Generation of nearshore bars by multi-domain hybrid numerical model." J. Coastal Res., 15(4), 89-901.

Leont'yev, I. O. (2003). "Modeling erosion of sedimentary coasts in the western Russian Arctic.” Coastal Eng., 47(4), 413-429.

Li, J. C., Liu, Q. Q., and Zhou, J. F. (2003). "Environmental mechanics research in China." Adv. Appl. Mech., 39, 217-306.

Li, Z. H., and Davies, A. G. (1996). "Towards predicting sediment transport in combined wave-current flow." J. Waterw., Port, Coastal, Ocean Eng., 122(4), 157-164.

Morton, R. A. (2002). "Factors controlling storm impacts on coastal barriers and beaches-A preliminary basis for near real-time forecasting." J. Coastal Res., 18(3), 486-501.

Morton, R. A., and Sallenger, A. H. (2003). "Morphological impacts of extreme storms on sandy beaches and barriers." J. Coastal Res., 19(3), 560-573.

Nielsen, P. (1992). "Coastal bottom boundary layers and sediment transport." Advanced Series on Ocean Engineering, World Scientific Publishing, Singapore, Vol. 4.

Noye, J. (1999). Modeling coastal sea processes, World Scientific, Singapore.

Orviku, K., Jaagus, J., Kont, A., Ratas, U., and Rivis, R. (2003). "Increasing activity of coastal processes associated with climate change in Estonia." J. Coastal Res., 19(2), 364-375.

Rajaona, R. D. (1995). "Sediment transport mechanisms in coastal environments and rivers." Appl. Mech. Rev., 48(9), 547-609.

Stone, G. W., Grymes, J. M., Dingler, J. R., and Pepper, D. A. (1997). "Overview and significance of hurricanes on the Louisiana coast, USA.” J. Coastal Res., 13(3), 656-669.

Vellinga, P. (1982). "Beach and dune erosion during storm surges." Coastal Eng., 6(4), 361-387.

Walker, D. J., and Rana, M. Y. (1999). "Modeling coastal processes on sandy beaches." Modeling coastal sea processes J. Noye, ed., 317341.

Wang, X. N. (1991). "Research and applications of forecasting model of a typhoon surges in China Seas." Advances in Water Sci., 2(1), 1-10 (in Chinese).

Wilcock, P. R. (1993). "Critical shear stress of natural sediments." $J$. Hydraul. Eng., 119(4), 491-505.

Yin, Q. J. (1985). "Numerical simulation of No. 7203 storm surge in Bohai Bay and some characteristcs of storm surges." Acta Oceanol. Sin., 7(3), 367-373 (in Chinese).

Zheng, J., and Robert, G. D. (1997). "Numerical models and intercomparisons of beach profile evolution." Coastal Eng., 30(3-4), 169-201.

Zhou, J. F., and Li, J. C. (2000). "Mixing and sediment transport in estuaries." Acta Mech. Sin., 32(5), 523-531 (in Chinese).

Zhou, J. F., Li, J. C., and Liu, H. D. (2000). "Influences of the waterway project in the Yangtze River Estuary on sediment transport." Stochastic Hydraulics '00, Proc. 8th Int. Symp. on Stochastic Hydraulics, A. A. Balkema, Rotterdam, The Netherlands, 333-341.

Zhou, J. F., Liang, L., and Li, J. C. (2001). "Modeling storm surge induced currents." Acta Mech. Sin., 33(6), 729-740 (in Chinese). 